\title{
Identification of the hysteretic behaviour of a partial-strength steel-concrete moment-resisting frame structure subject to pseudodynamic tests
}

\author{
Oreste S. Bursi ${ }^{1}$, Rosario Ceravolo ${ }^{2, *}$, , Silvano Erlicher $^{3}$ and Luca Zanotti Fragonara ${ }^{2}$ \\ ${ }^{1}$ DIMS, Department of Mechanical and Structural Engineering, University of Trento, Trento, Italy \\ ${ }^{2}$ DISTR, Department of Structural and Geotechnical Engineering, Politecnico di Torino, Torino, Italy \\ ${ }^{3}$ EGIS Industries, 4 rue Dolores Ibarruri, TSA 50012, Montreuil, Cedex 93188, France
}

\begin{abstract}
SUMMARY
In low-rise steel-concrete composite structures, moment-resisting frames can be designed to develop a ductile response in beam-to-column joints and column bases by activating flexural yielding of beams and end plates, shear yielding of column web panel zones and yielding of anchors. To evaluate the performance of these components under differing earthquake intensities, a series of pseudodynamic, quasistatic cyclic and vibration tests were carried out on a two-storey two-bay moment resisting structure. The performance-based seismic design and control of these structures requires that stiffness degradation, strength deterioration and slip are properly modelled. In this context, compact hysteretic models can play a key role and must therefore be striven for. Nonetheless, relevant techniques, like nonlinear system identification, are far from representing standard and reliable tools for the dynamic characterization of full-scale structural systems. With this objective in mind, we present a restoring force surface-based technique applied to pseudodynamic test data, in view of the nonlinear identification of multistorey frames. The technique is developed by means of a parametric approach, where a time-variant stiffness operator is coupled to a modified Bouc-Wen model that allows both for slip and for degradation in stiffness. Strength deterioration is indirectly taken into account too. We also show how model-based parameters can be correlated to the damage process progressively observed both in the structure and in its components. Finally, the predictive capabilities of the identified model are highlighted. Copyright (C) 2012 John Wiley \& Sons, Ltd.
\end{abstract}

Received 17 May 2011; Revised 24 December 2011; Accepted 25 December 2011

KEY WORDS: pseudodynamic testing; nonlinear identification; restoring force surface technique; parametric identification; Bouc-Wen model; pinching

\section{INTRODUCTION}

\subsection{Background and motivation}

Performance-based earthquake engineering (PBEE) is still under development and focuses on innovative structural systems aimed at enhancing functionality, operability and safety [1]. The use of base-isolation systems, passive dampers and semi-active devices is typical [2]. The PBEE framework is based on performance objectives expressed as the probability of exceeding specified performance levels. Performance levels are quantified as expressions relating generic structural variables, for example, demand and capacity. Common probabilistic analysis tools are then used to convolute both the randomness and uncertainty characteristics of ground motion intensity, structural

\footnotetext{
*Correspondence to: Rosario Ceravolo, DISTR, Department of Structural and Geotechnical Engineering, Politecnico di Torino, Torino, Italy.

†E-mail: rosario.ceravolo@polito.it
} 
demand and structural system capacity, to derive an expression for the probability of achieving a specified performance level. Clearly, these developments need to be checked for actual performance before they are confidently transferred to real design. Therefore, the advancement of the PBEE approach requires: (i) data obtained from testing, especially for those issues that are pertinent to collapse, rate-of-loading, full scale and structural systems, where data are scarce; (ii) hysteretic models with stiffness degradation, strength deterioration and pinching capabilities, simple enough to permit extensive parametric simulations. In addition, the availability of hysteretic mathematical models easily allows for the development of control laws for nonlinear structural hysteretic systems [3]. Within this framework, our research tries to combine the benefit of: (i) the classical pseudodynamic (PsD) testing technique, as applied to structures for which strain-rate effects can be neglected [4], and (ii) nonlinear identification techniques of complex nonlinear systems, capable of capturing hereditary characteristics of inelastic restoring forces of structures [5].

Notwithstanding the significant strides made in the field of identification of hysteretic systems, see Masri et al. [6], among others, one is led to the conclusion that these advances did not find their way into the realm of applications; in fact, there is a paucity of papers that apply this or similar techniques to full-scale and/or scaled-down structures. In greater detail, (i) Bursi et al. tried to identify the full-scale two-storey two-bay steel concrete composite structure [7], studied in depth herein; Hernandez-Garcia et al. [8] analysed a test specimen made of a 4-DOF system endowed with $0.3 \times 0.3 \times 0.025 \mathrm{~m}$ slabs and columns $0.177 \mathrm{~m}$ tall; Loh et al. [9] considered a one-storey two-bay reinforced concrete frame $2.55 \mathrm{~m}$ tall and $4.7 \mathrm{~m}$ wide; Ma et al. [10] studied wood joints made of plywood gusset plates of about $0.4 \times 0.5 \mathrm{~m}$. Therefore, the identification of realistic hysteretic systems is precisely our objective in this paper.

Identification methods for nonlinear systems can be classified as parametric and nonparametric, respectively [11]. In the former case, an a priori selection of a specific model, for example, the Bouc-Wen model [12] is needed, and the identification process is based on determination of the coefficients of that model. Nonparametric methods, like neural networks, do not require any assumption on the type and localisation of structural nonlinearity; however, identified quantities cannot be directly correlated to the equations of motion. Classical nonparametric methods are generally based on the extension of the restoring force surface (RFS) method [13]; this technique represents a system restoring force in terms of a doubly indexed orthogonal polynomial series involving system state variables. Benedettini et al. [14] approximated the surface of the time derivative of a restoring force with a set of basis functions, including both the velocity and the force itself. Masri et al. [6] extended that approach by using displacements.

When a structural system subject to earthquake loading exhibits degradation or behaves as time variant, we must consider instantaneous and possibly online estimation techniques to perform a nonlinear identification. Among instantaneous-based identification techniques, we mention those that operate in the time domain, such as the approach of Smyth et al. [15], where an extended Kalman filter is applied to a state-space representation of the equations of motion. This technique allows for linearization of the system through a Jacobian and the recursive update of the model parameters, when new observations are available. Along the same lines, $\mathrm{Wu}$ and Smyth [16] employed the unscented Kalman filter technique, which can treat more general nonlinearity. The idea behind the unscented Kalman filter is that it is easier to approximate a probability distribution than to approximate an arbitrary nonlinear function or transformation. Similarly, Spiridonakos et al. [17] and Du and Wang [18] employed families of autoregressive moving average models.

In this work, we consider the instantaneous-based identification technique applied to nonlinear systems, which relies on a time-frequency approach [5, 19-22]. The entailing formulation determines model parameters that minimize an error function between time-frequency representations of measured and simulated signals, respectively. The representation adopted here is a spectrogram [21]. The choice of the time-frequency technique was made because of its robustness, that is, its capability to clearly identify both signal events that manifest during a short time interval (time localization) and signal components, which are concentrated at particular Fourier frequencies, such as sinusoids (frequency localization). Therefore, to identify the hysteretic behaviour of a nonlinear steel-concrete composite structure, we can combine the instantaneous-based identification technique with a parametric method to provide instantaneous estimates of parameters. 


\subsection{Scope}

The above-mentioned RFS-based technique, based on a parametric approach and applied to a nonlinear time variant system, is used in this study. It allows a time-variant stiffness operator coupled to a modified Bouc-Wen model, having both degradation of stiffness and slip to be identified. Strength deterioration too is indirectly taken into account. In greater detail, the application is made on a ductile partial-strength steel-concrete composite structure subject to pseudodynamic tests, characterized by earthquake levels ranging from $0.1 g$ to $1.8 g$ PGA [23]. Its response characterization represents a challenging problem, which involves flexural yielding of beam ends and end plates, shear yielding of column web panel zones and yielding of anchors [24]. In this respect, we summarise first the RFS method based on a parametric approach and the subsequent identification in the time-frequency domain. Then, a modified Bouc-Wen hysteretic model, capable of taking into account both degradation in stiffness and slip for a 2-DOF chain-like system is formulated. Successively, the main characteristics, the test programme and the main results of a steel-concrete composite structure are presented. Then, the parametric identification of the hysteretic laws of a condensed 2-DOF frame of this structure is carried out and the correlation between model-based parameters and its degrading dynamic response is discussed. Lastly, the whole procedure is validated by a comparison between the response predicted by the identified hysteretic models endowed with time-invariant parameters and relevant experimental data. Necessary developments are highlighted.

\section{IDENTIFICATION TECHNIQUES FOR NONLINEAR SYSTEMS}

\subsection{The RFS method based on a parametric approach}

The central idea of the RFS method in agreement with Benedettini et al. [14] is that the time derivative of a restoring force can be expressed both in terms of velocity and of restoring force of the system itself. With regard to an SDOF nonlinear system, its motion can be represented as

$$
m \ddot{x}+f=u(t)
$$

where $m$ represents the mass of the system, $x$ the displacement, $u$ the external force, $f$ the internal restoring force and the superposed dot indicates time differentiation. The method applied to a class of hysteretic systems assumes that the restoring force $f(x, \dot{x})$ can be described as

$$
\dot{f}=\dot{f}(\dot{x}, f ; \mathbf{p})
$$

where the analytical function $\dot{f}(\cdot)$ depends both on the state variables $\dot{x}$ and $f$, and on a model parameter vector $\mathbf{p}$.

The RFS method is simplified, if one pursues a parametric approach [9]. In view of the application considered later, we can insert in (2) a hysteretic oscillator governed by the Bouc-Wen model [12, 25-27] associated to a second-order structural system, that reads

$$
\dot{f}=\left[A-(\beta \cdot \operatorname{sgn}(\dot{x} \cdot f)+\gamma)|f|^{n}\right] \dot{x}
$$

where the parameters $A, \beta$ and $\gamma$ control the size and shape of each hysteretic loop; and decreasing values of $n$ smooth the transition from the elastic to the post-elastic regime; sgn(.) is the signum function. To capture the degradation of systems subject to seismic loads, stiffness degradation and strength deterioration were typically modulated by means of additional parameters function of the dissipated energy (see, Ref. [28] among others). Nonetheless, to avoid the identification of additional parameters with related complex laws, $A, \beta$ and $\gamma$ might be assumed as time variant. Therefore, both the initial stiffness $A$ and the asymptotic yield strength 


$$
f_{y}=\left[\frac{A}{\beta+\gamma}\right]^{\frac{1}{n}}
$$

will be functions of time. If we fix $n$ because of its small influence on the identification, it is evident that the identified parameters $A, \beta, \gamma$ will depend on time and on the PGA level. Although we accept $A$ to be time variant to allow for stiffness degradation, we intend to use an identified hysteretic model with timeinvariant values of $\beta$ and $\gamma$. This is the reason why we will test the predictive capabilities of the identified hysteretic models in Section 6 by means of averaged parameters per PGA level. The average process will also be applied to slip parameters introduced in Section 3.1.

A careful reader can observe from (3) that $\dot{f}$ is homogeneous of order one with respect to $\dot{x}$, and therefore, $f$ is 'rate-independent'. This feature complies well with results provided by conventional PsD tests, where strain-rate effects can be neglected.

\subsection{Identification in the time-frequency domain}

The identification of the parameter vector $\mathbf{p}$ in (2), defined as $\{A, \beta, \gamma, n\}$ because of (3), could be performed in the time domain [19]. There, an error function $Q(\mathbf{p})$ could be minimized through

$$
Q(\mathbf{p})=\int_{-\infty}^{+\infty}\left[|v(t, \mathbf{p})|-\left|v_{m}(t)\right|\right]^{2} \mathrm{~d} t \rightarrow \mathbf{p}_{i d}=\arg \left[\min _{\forall \mathbf{p}} Q(\mathbf{p})\right]
$$

where $v$ is a state variable, namely a nonlinear function of $\mathbf{p}$, while $v_{m}$ is a measured response of the same state variable, both functions of $t$. In greater detail, $v$ could represent a displacement variable and hence (5) would provide better fitting in the low-frequency range. Conversely $v$ could define an acceleration variable, and so (5) would provide better fitting in the high frequency range. In any case, the optimisation process via (5) lacks frequency localisation, that is, it cannot use direct information about the temporal localization of harmonic components. As a result, to localise the nonlinear evolution of system parameters both in frequency and time [21, 22], we redefine the error function as follows:

$$
Q(t, \mathbf{p})=\left\|\int_{-\infty}^{+\infty}\left[\tilde{T}_{\ddot{x}}(t, f ; \mathbf{p})-T_{\ddot{x}_{m}}(t, f)\right] \mathrm{d} f\right\| \rightarrow \mathbf{p}_{i d}(\bar{t})=\arg \left[\min _{\forall \mathbf{p}, t=\bar{t}} Q(t, \mathbf{p})\right]
$$

where $T_{\ddot{x}}($.$) denotes the time-frequency transform operator applied to the acceleration variable \ddot{x}$. At any instant $\bar{t}$, the minimisation process leads to an associated optimal vector $\mathbf{p}_{i d}(\bar{t})$, which provides instantaneous estimates of the model parameters in (3). In this context, deterministic minimisation methods such as the Newton, quasi-Newton, or pattern search algorithms are among the best candidates. As specified in Section 5.1, we used a pattern search algorithm.

\section{A MODIFIED BOUC-WEN MODEL FOR THE PARAMETRIC IDENTIFICATION OF A 2- DOF SYSTEM}

\subsection{A modified Bouc-Wen model}

When subject to intense earthquake excitation, structural systems typically dissipate energy through hysteretic effects. In this context the Bouc-Wen model is often used to describe the hysteretic behaviour of structural systems because of its compact and continuous representation of hysteresis [25-27]. Several studies on this model were proposed during recent decades to understand its properties (see Refs. [29, 30], among others). Other studies mainly focused on rendering the model capable of capturing some specific behaviour of engineering materials (see for instance, Refs. [31, 32]), where emphasis was given to pinching, stiffness deterioration and strength degradation. Because here we deal with the hysteretic response of a steel-concrete composite structure [33], the so-called pinching or slip model suggested by Li et al. [31] is appropriate enough. 
Along this line [31], to account for slip in Equation (3), an inverse sigmoid function is introduced [34]

$$
x_{s}(f)=s \frac{\left(1-e^{-\mu_{s} \cdot f}\right)}{\left(1+e^{-\mu_{s} \cdot f}\right)}
$$

where $f$ defines a spring force, $s$ the amount of slip and $\mu_{s}$ a coefficient that controls the inverse of the tangent near the origin. This function is depicted in Figure 1 where, in agreement with Refs. [31, 32], $s$ precisely defines only half of the total slip. In greater detail, this slip model is expected to capture several phenomena in a steel-concrete composite structure, like detachments at steel-concrete interfaces, bolt clearances, clearances at beam-to-column joints, clearances at column bases, etc.

The slip spring governed by (7) is assumed to operate in series with a Bouc-Wen hysteretic spring, that is,

$$
x=x_{s}+x_{\mathrm{BW}}
$$

This assumption is illustrated in Figure 2.

From Equation (7) one can define the inverse of the tangent stiffness $k_{s}(f)$ associated with slip, that is

$$
\frac{1}{k_{s}(f)}=\frac{\mathrm{d} x_{s}(f)}{\mathrm{d} f}=\frac{2 \mu_{s} s}{\left(1+e^{\mu_{s} f}\right)^{2}} e^{\mu_{s} f}>0
$$

Similarly, the tangent stiffness of the Bouc-Wen model is obtained from (3) by derivation with respect to $x_{\mathrm{BW}}$ (in the system with springs in series $x$ in Equation (3) is replaced with $x_{\mathrm{BW}}$ ), that is,

$$
k_{\mathrm{BW}}\left(f, \operatorname{sgn}\left(\dot{x}_{\mathrm{BW}} \cdot f\right)\right)=A-\left(\beta \cdot \operatorname{sgn}\left(\dot{x}_{\mathrm{BW}} \cdot f\right)+\gamma\right)|f|^{n}
$$

Because $A>0$ and $k_{\mathrm{BW}}(f, \operatorname{sgn}(\dot{x} \cdot f))>0$ for all given $f$ and $\dot{x}$, then $\operatorname{sgn}(\dot{x})=\operatorname{sgn}\left(\dot{x}_{\mathrm{BW}}\right)=\operatorname{sgn}\left(\dot{x}_{s}\right)$. In other words, an increase of $f$ entails an increase of $x_{\mathrm{BW}}, x_{s}$ and, as a result of (8), of $x$. Thus, the stiffness formulation of the Bouc-Wen model with slip reads

$$
\dot{f}=k_{s}(f) \cdot \dot{x}_{s}=k_{\mathrm{BW}}(f, \operatorname{sgn}(\dot{x} \cdot f)) \cdot \dot{x}_{\mathrm{BW}}
$$

and the equivalent stiffness of the springs in series, $\tilde{k}$, becomes

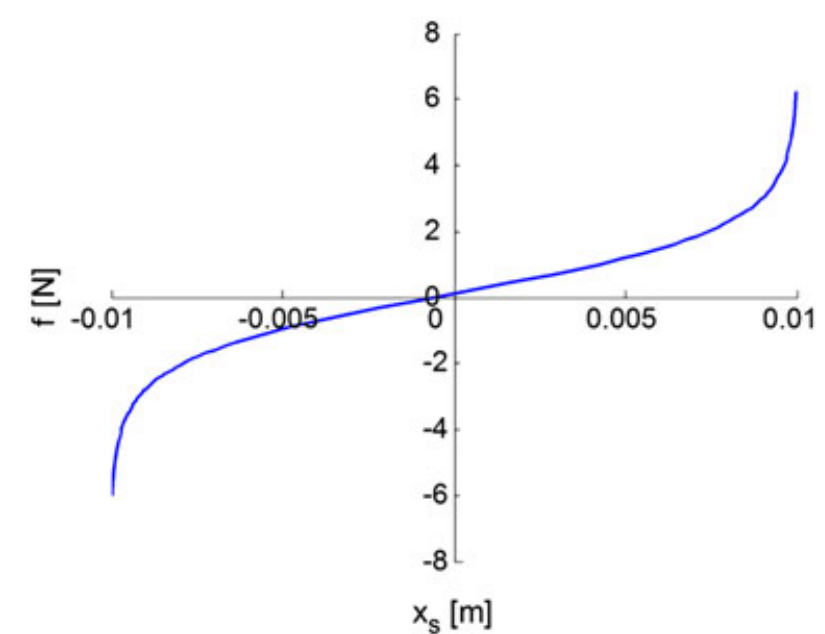

Figure 1. A slip function. 




Figure 2. Slip and Bouc-Wen springs in series for an SDOF system.

$$
\tilde{k}(f, \operatorname{sgn}(\dot{x} \cdot f))=\frac{k_{s}(f) k_{\mathrm{BW}}(f, \operatorname{sgn}(\dot{x} \cdot f))}{k_{s}(f)+k_{\mathrm{BW}}(f, \operatorname{sgn}(\dot{x} \cdot f))}=\left(\frac{2 \mu_{s} s}{\left(1+e^{\mu_{s}}\right)^{2}} e^{\mu_{s} f}+\frac{1}{A-(\beta \operatorname{sgn}(\dot{x} \cdot f)+\gamma)|f|^{n}}\right)^{-1}
$$

To sum up, the differential system for an SDOF model endowed with the Bouc-Wen hysteretic law (3) in series with a slip component, takes the following form:

$$
\left\{\begin{array}{c}
m \ddot{x}+f=-m \ddot{u} \\
\dot{f}=\tilde{k}(f, \operatorname{sgn}(\dot{x} \cdot f)) \cdot \dot{x}
\end{array}\right.
$$

If we define $\bar{k}$ as the equivalent stiffness that we would obtain by excluding hysteresis (setting $\beta=\gamma=0$ ) from Equation (12), it can be proven that system (13) is equivalent to

$$
\left\{\begin{array}{l}
m \ddot{x}+f=-m \ddot{u} \\
\dot{f}=\bar{k}(f)\left(\dot{x}-\dot{x}_{n l}\right) \\
\dot{x}_{n l}=\frac{1}{A} \beta^{p}(f, \operatorname{sgn}(\dot{x})) \dot{x}_{\mathrm{BW}} \\
\frac{1}{\bar{k}(f)}=\frac{1}{A}+\frac{1}{k_{s}(f)}
\end{array}\right.
$$

with

$$
\beta^{p}(f, \operatorname{sgn}(\dot{x}))=(\beta \operatorname{sgn}(\dot{x} \cdot f)+\gamma)|f|^{n}
$$

and

$$
\dot{x}_{\mathrm{BW}}=\dot{x}-\dot{x}_{s}=\dot{x}-\frac{\dot{f}}{k_{s}(f)}
$$

This formulation based on a model with slip and hysteresis is easier to generalise to the 2-DOF case than Equation (13). 


\subsection{Model for a two-storey system}

In this subsection, the modified Bouc-Wen model will be extended to chain-like frame systems. With reference to the two-storey system shown in Figure 3 and in accordance with the scheme of Figure 2, one can express the global displacements, by summing both linear and nonlinear components. First, we introduce the nonlinearity caused by slip, assuming for the linear part a general symmetric $2 \times 2$ stiffness matrix, while nonlinear restoring forces are combined according to a chain-like system, that is,

$$
\left\{\begin{array}{l}
x_{1} \\
x_{2}
\end{array}\right\}=\left[\begin{array}{ll}
k_{11} & k_{12} \\
k_{12} & k_{22}
\end{array}\right]_{e l}^{-1} \cdot\left\{\begin{array}{l}
f_{1} \\
f_{2}
\end{array}\right\}+\left\{\begin{array}{c}
x_{s, 1}\left(f_{1}+f_{2}\right) \\
x_{s, 2}\left(f_{2}\right)+x_{s, 1}\left(f_{1}+f_{2}\right)
\end{array}\right\}
$$

where

$$
\mathbf{K}_{e l}=\left[\begin{array}{ll}
k_{11} & k_{12} \\
k_{12} & k_{22}
\end{array}\right]_{e l}
$$

represents the condensed stiffness matrix of the underlying linear system, which will be time variant during the identification process; $x_{s, 1}$ and $x_{s, 2}$ define the nonlinear interstorey drifts at the lower and upper storey, respectively. These displacements are assumed to depend on the forces $f_{1}+f_{2}$ and $f_{2}$, respectively, according to a shear-type behaviour.

Equation (17) may be rewritten in an explicit form, in accordance with Equation (7), and differentiated with respect to time

$$
\begin{aligned}
& \left\{\begin{array}{l}
\dot{x}_{1} \\
\dot{x}_{2}
\end{array}\right\}=\left[\begin{array}{ll}
k_{11} & k_{12} \\
k_{12} & k_{22}
\end{array}\right]_{e l}^{-1} \cdot\left\{\begin{array}{l}
\dot{f}_{1} \\
\dot{f}_{2}
\end{array}\right\} \\
& +\left[\begin{array}{cc}
\frac{2 e^{\mu_{s, 1}\left(f_{1}+f_{2}\right)} \mu_{s 1} s_{1}}{\left(1+e^{\mu_{s, 1}\left(f_{1}+f_{2}\right)}\right)^{2}} & \frac{2 e^{\mu_{s, 1}\left(f_{1}+f_{2}\right)} \mu_{s, 1} s_{1}}{\left(1+e^{\mu_{s, 1}\left(f_{1}+f_{2}\right)}\right)^{2}} \\
\frac{2 e^{\mu_{s, 1}\left(f_{1}+f_{2}\right)} \mu_{s, 1} s_{1}}{\left(1+e^{\mu_{s, 1}\left(f_{1}+f_{2}\right)}\right)^{2}} & \frac{2 e^{\mu_{s, 2} f_{2}} \mu_{s, 2} s_{2}}{\left(1+e^{\mu_{s, 2} f_{2}}\right)^{2}}+\frac{2 e^{\mu_{s, 1}\left(f_{1}+f_{2}\right)} \mu_{s, 1} s_{1}}{\left(1+e^{\mu_{s, 1}\left(f_{1}+f_{2}\right)}\right)^{2}}
\end{array}\right]\left\{\begin{array}{l}
\dot{f}_{1} \\
\dot{f}_{2}
\end{array}\right\}
\end{aligned}
$$

The second part of (19) clearly assumes the form of the product of a force dependent tangent flexibility matrix, $\mathbf{K}_{\mathbf{s}}^{-1}$, associated to slip contribution, with the time-derivative of the force vector $\mathbf{f}=\left(f_{1}, f_{2}\right)^{T}$. By inversion of Equation (19), we can define $\overline{\mathbf{K}}(\mathbf{f})$, such that $\dot{\mathbf{f}}=\overline{\mathbf{K}}(\mathbf{f}) \cdot \dot{\mathbf{x}}$ with $\dot{\mathbf{x}}=\left(\dot{x}_{1}, \dot{x}_{2}\right)^{T}$, which extends to a 2-DOF system, the stiffness operator $\bar{k}(f)$ introduced in Equation (14d). Therefore, the equations of motion associated with the frame system assume the following form:

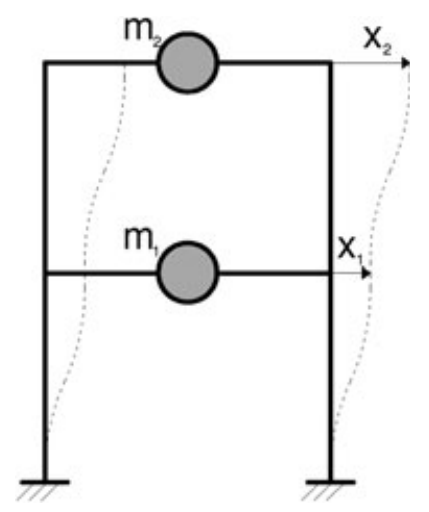

Figure 3. A chain-like two-storey frame. 


$$
\left\{\begin{array}{c}
\mathbf{M} \cdot \ddot{\mathbf{x}}+\mathbf{f}=-\mathbf{M} \cdot \ddot{\mathbf{u}}_{g} \\
\dot{\mathbf{f}}=\overline{\mathbf{K}}(\mathbf{f}) \cdot \dot{\mathbf{x}} \\
\overline{\mathbf{K}}(\mathbf{f})^{-1}=\mathbf{K}_{e l}{ }^{-1}+\mathbf{K}_{s}(\mathbf{f})^{-1}
\end{array} .\right.
$$

To take into account hysteresis, a Bouc-Wen model is assumed to be in series with both the slip and the linear spring, as shown in Figure 2 for an SDOF system. Hence, the system (20) is modified as follows:

$$
\left\{\begin{array}{l}
\mathbf{M} \cdot \ddot{\mathbf{x}}+\mathbf{f}=-\mathbf{M} \cdot \ddot{\mathbf{u}}_{g} \\
\dot{\mathbf{f}}=\overline{\mathbf{K}}(\mathbf{f})\left(\dot{\mathbf{x}}-\dot{\mathbf{x}}_{\mathrm{nl}}\right) \\
\dot{\mathbf{x}}_{\mathrm{nl}}=\mathbf{K}_{e l}{ }^{-1} \boldsymbol{\beta}^{p} \dot{\mathbf{x}}_{\mathrm{BW}} \\
\overline{\mathbf{K}}(\mathbf{f})^{-1}=\mathbf{K}_{e l}{ }^{-1}+\mathbf{K}_{s}(\mathbf{f})^{-1}
\end{array}\right.
$$

where $\dot{\mathbf{x}}_{\mathrm{BW}}=\dot{\mathbf{x}}-\dot{\mathbf{x}}_{s}=\dot{\mathbf{x}}-\mathbf{K}_{s}(\mathbf{f})^{-1} \dot{\mathbf{f}}$. The matrix $\boldsymbol{\beta}^{p}$ defines the nonlinear hysteretic part $\dot{\mathbf{x}}_{\mathrm{nl}}$ of the total displacement $\mathbf{x}$,

$$
\begin{aligned}
\boldsymbol{\beta}^{p} & =\boldsymbol{\beta}^{p}\left(f_{1}, f_{2}, \dot{x}_{\mathrm{BW}, 1}, \dot{x}_{\mathrm{BW}, 2} ; \beta_{1}, \gamma_{1}, n_{1}, \beta_{2}, \gamma_{2}, n_{2}\right)= \\
& =\left[\begin{array}{cr}
\dot{f}_{p}\left(f_{1}+f_{2}, \dot{x}_{\mathrm{BW}, 1} ; \beta_{1}, \gamma_{1}, n_{1}\right)+\dot{f}_{p}\left(f_{2}, \dot{x}_{\mathrm{BW}, 2}-\dot{x}_{\mathrm{BW}, 1} ; \beta_{2}, \gamma_{2}, n_{2}\right) & -\dot{f}_{p}\left(f_{2}, \dot{x}_{\mathrm{BW}, 2}-\dot{x}_{\mathrm{BW}, 1} ; \beta_{2}, \gamma_{2}, n_{2}\right) \\
-\dot{f}_{p}\left(f_{2}, \dot{x}_{\mathrm{BW}, 2}-\dot{x}_{\mathrm{BW}, 1} ; \beta_{2}, \gamma_{2}, n_{2}\right) & \dot{f}_{p}\left(f_{2}, \dot{x}_{\mathrm{BW}, 2}-\dot{x}_{\mathrm{BW}, 1} ; \beta_{2}, \gamma_{2}, n_{2}\right)
\end{array}\right]
\end{aligned}
$$

supposing a chain-like hysteretic nonlinearity, and $\dot{f}_{p}$ denotes a Bouc-Wen type of hysteresis

$$
\dot{f}_{p}\left(f, \dot{x}_{\mathrm{BW}} ; \beta, \gamma, n\right)=|f|^{n}\left[\beta \cdot \operatorname{sgn}\left(f \cdot \dot{x}_{\mathrm{BW}}\right)+\gamma\right]
$$

We assume $\beta_{i}>0, \gamma_{i} \in\left[-\beta_{i}, \beta_{i}\right]$ and $n_{i}>0$ in Equation (23), thus, a softening behaviour is simulated. Additional information about Bouc-Wen model properties can be found in [12, 29, 30].

\section{THREE-DIMENSIONAL STRUCTURE, TEST PROGRAMME AND RESULTS OF PSD} TESTS

\subsection{The three-dimensional test structure}

The full scale steel-concrete composite structure, whose prototype is shown in Figure 4(a), was constructed of three identical moment-resisting frames, arranged at a spacing of $3.0 \mathrm{~m}$. It is depicted in Figure 4(b). Each frame consisted of two bays of 5.0 and $7.0 \mathrm{~m}$, respectively, and two storeys $3.5 \mathrm{~m}$ in height, with transverse $\mathrm{X}$-shaped sway braces. Steel-concrete composite beams shown in Figure 4(c) were made up of IPE300 steel profiles connected by full shear connection studs to a 15cm-thick concrete slab, cast on profiled sheeting. HEB260 and HEB280 partially-encased steelconcrete composite columns were used as shown in Figure 4(c) and high-ductile partial-strength composite beam-to-column joints were designed to provide plastic joint rotations of $35 \mathrm{mrad}$ associated with a residual strength of at least $80 \%$ of their maximum value. The slabs were reinforced with transversal reinforcing bars to activate strut and tie mechanisms between slabs and columns. Braconi et al. [23, 24] provided a complete description of the structure, including the design methodology and structural performance data.

\subsection{Dynamic, pseudodynamic and cyclic tests}

Ambient vibration tests, stepped sinusoidal tests and shock hammer tests were performed on the undamaged structure to allow for the definition of $\mathbf{K}_{e l}$ in (18). Moreover, the structure was identified at different stages. Successively, in accordance with the PBEE approach, we carried out a series of 
(a)
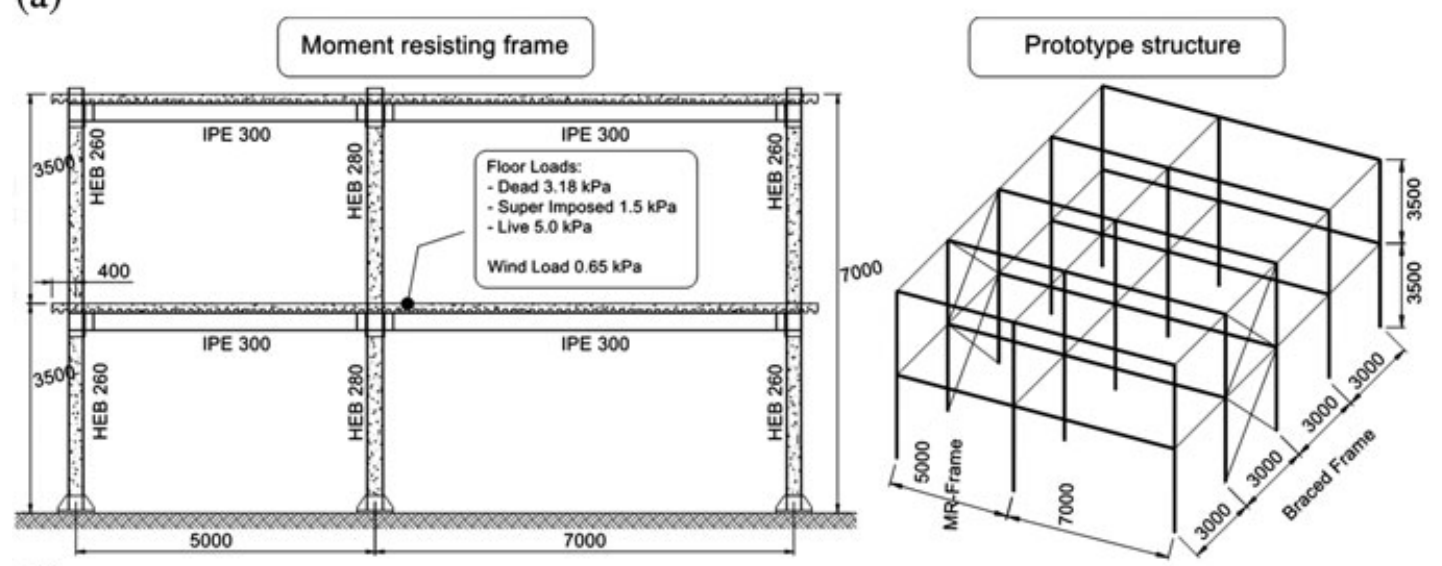

(b)
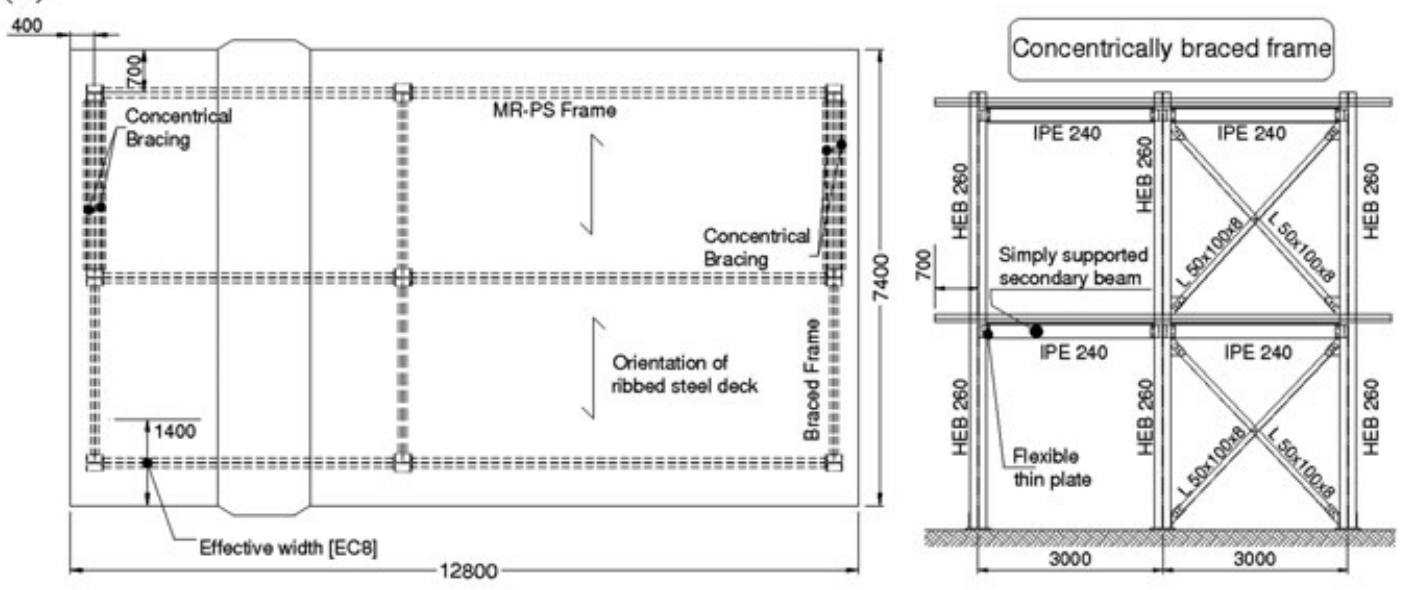

(c)

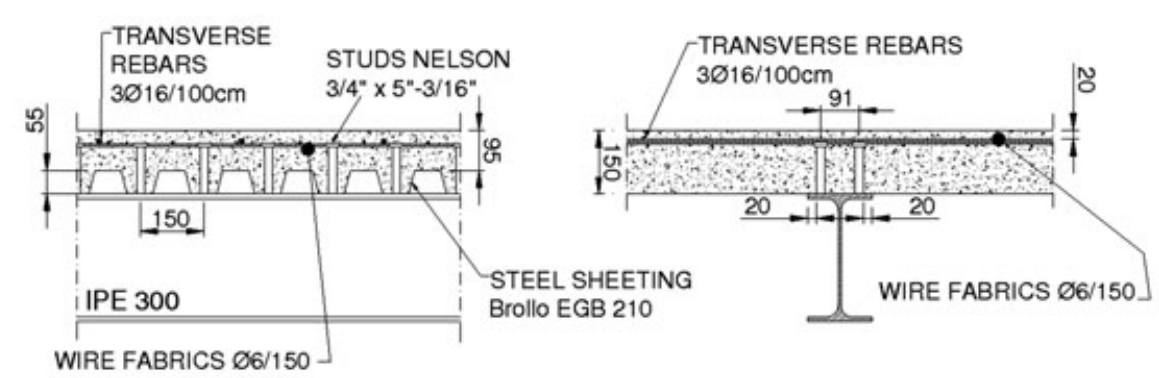

Composite beam
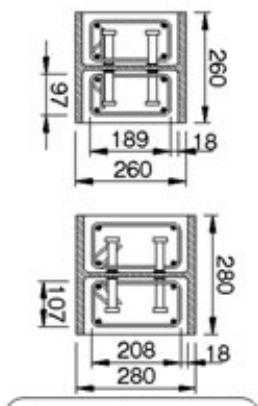

Composite columns

Figure 4. Prototype structure: (a) moment-resisting frame and relevant structure; (b) plan view of the prototype structure tested at JRC and concentrically braced frame; and (c) main features of composite beams and columns (after Ref. [23]).

four PsD tests at increasing ground motion amplitudes, to examine the response of the structure corresponding to various limit states or anticipated performance levels. The chosen test programme is listed in Table I. In addition to PsD tests, to induce severe damage to the structure and allow failure mechanisms of structural components to be examined, a final cyclic quasistatic test with stepwise increasing large amplitudes was carried out. The reasons why the structure was able to withstand such high values of PGA were discussed in depth elsewhere [24]. 
O. S. BURSI ET AL.

Table I. Summary of the test programme and performance objectives.

\begin{tabular}{lcll}
\hline Test & Vibration test & PsD test PGA $[g]$ & \multicolumn{1}{c}{ Performance objective } \\
\hline I & Phase I & - & Identification at the undamaged state \\
1 & - & 0.10 & Pseudoelastic state \\
2 & - & 0.25 & Serviceability limit state (SLS) \\
3 & - & 1.40 & Life safe limit state (LSLS) \\
II & Phase II & 1.80 & Identification at the LSLS \\
4 & - & Cyclic & Collapse onset limit state (COLS) \\
5 & - & - & Max top displacement equal to 300 mm \\
III & Phase III & Identification beyond the COLS \\
\hline
\end{tabular}

To perform the numerical integration of the overall system, a digital controller was used; this managed lateral displacements and forces at each level of the test structure. The continuous PsD method with an explicit $\alpha$-Newmark method and a time step of $0.002 \mathrm{~s}$ was adopted. For each of the three moment-resisting frames masses equal to $83,300 \mathrm{~kg}$ and $85,600 \mathrm{~kg}$ were specified in the equations of motion, at the bottom and top storey, respectively; these represent the seismic weights considered in the design. No viscous damping forces were included in the dynamic equilibrium equations, the damping being small and variable. However, friction forces were included in reaction forces measured through actuators. The ratio between the duration of the accelerogram in the laboratory and the actual record was greater than 1000, reaching values of up to 4000 during the strong motion phase - large amplitudes of PsD tests N. 3 and 4 - to keep both damping and energy errors below $5 \%$.

\subsection{Results of pseudodynamic tests}

To be able to correlate structural damage with the results of identification presented in the next section, the main results of PSD tests are summarized here. The objectives of the first PsD test, characterized by a $\mathrm{PGA}=0.1 \mathrm{~g}$, are: (i) to collect data on the elastic uncracked dynamic properties of the test frame; (ii) to verify the adequateness of the test set-up; and (iii) to check the accuracy of the PsD algorithm. Therefore, relevant maximum interstorey drifts (ID) reported in Table II are quite small, detachments in slabs between concrete and structural steel around columns and in column bases are negligible and cracking is limited.

The objective of PsD test N. 2 reported in Table I, was to approach the onset of yield with very limited damage to the structure, corresponding to the serviceability limit state (SLS) [24]. During the test, peak ID values reached approximately $0.6 \%$ at both levels as indicated in Table II. Visual inspection after the test indicated no visible gap between beam end plates and column flanges;

Table II. Structural behaviour properties for different PGA levels.

\begin{tabular}{|c|c|c|c|c|c|c|}
\hline & \multicolumn{3}{|c|}{ Lower storey } & \multicolumn{3}{|c|}{ Upper storey } \\
\hline PGA & $\begin{array}{l}\text { Maximum } \\
\text { ID [\%] }\end{array}$ & $\begin{array}{l}\text { Maximum } \\
\text { gap }[\mathrm{m}]\end{array}$ & Observed phenomena & $\begin{array}{c}\text { Maximum } \\
\text { ID [\%] }\end{array}$ & $\begin{array}{c}\text { Maximum } \\
\text { gap }[\mathrm{m}]\end{array}$ & Observed phenomena \\
\hline $0.10 g$ & 0.28 & 一 & $\begin{array}{l}\text { Small cracks in the } \\
\text { slab around columns }\end{array}$ & 0.35 & 一 & $\begin{array}{l}\text { Small cracks in the } \\
\text { slab around columns }\end{array}$ \\
\hline $0.25 g$ & 0.6 & - & $\begin{array}{l}\text { Cracks in the slab and } \\
\text { under base plates }\end{array}$ & 0.6 & - & $\begin{array}{l}\text { Cracks in the slab and } \\
\text { under base plates }\end{array}$ \\
\hline $1.40 g$ & 2.5 & 0.0038 & $\begin{array}{l}\text { Concrete crush in the } \\
\text { slab. Joint yielding. } \\
\text { Anchors yielding. }\end{array}$ & 3.2 & 0.0017 & $\begin{array}{l}\text { Concrete crush in the } \\
\text { slab. Joint yielding. } \\
\text { Anchors yielding. }\end{array}$ \\
\hline $1.80 \mathrm{~g}$ & 3.8 & 0.0045 & $\begin{array}{l}\text { Concrete crush in the } \\
\text { slab. Joint yielding. } \\
\text { Column base joints } \\
\text { yielding. }\end{array}$ & 3.5 & 0.0032 & $\begin{array}{l}\text { Concrete crush in the } \\
\text { slab. Joint yielding. } \\
\text { Column base joints } \\
\text { yielding. }\end{array}$ \\
\hline
\end{tabular}


additional cracks developed in the concrete slab and thin cracks developed transversally in the mortar under the base plates in line with anchor rods. Slab cracking was more evident in the lower storey and at the external beam-to-column joints, see Figures 4(a) and (b), likely because of the higher rotation demand in the shorter and stiffer spans.

The objective of this third PsD test, characterized by a PGA $=1.40 \mathrm{~g}$, was to approach the life safe limit state conditions with inelastic joint rotations in beam-to-column joints of at least $35 \mathrm{mrad}$. Peak ID values reached $2.50 \%$ and $3.17 \%$ at bottom and top storeys, respectively. Peak rotations in exterior beam-to-column joints at the bottom storey approached $27.5 \mathrm{mrad}$. Yielding of beam end plates under both positive and negative bending moments could be readily observed at exterior joints, whereas shear yielding of column web panel zones seemed to dominate the response of interior joints. The crack pattern of the slab was similar to that observed in the PsD test N. 2 . However, the extent of cracking was significantly increased and crushing of the concrete slab against the column face was observed on the interior side of exterior columns, see Figure 5(a), and on both sides of the interior columns. No flexural concrete cracking or local steel flange instabilities were observed at steel column bases. However, significant rotation of column base joints developed during the test, reaching up to $21.7 \mathrm{mrad}$ at a height of $690 \mathrm{~mm}$ from the base joint as shown in Figure 5(b) for an interior column A-2. This rotation was mainly attributed to the extension of the anchor rods and large deformation of the grout filling in compression under the action of bending moments. At the end of the test, gaps left between concrete slab and steel column faces varied between 0.9 and $3.8 \mathrm{~mm}$ in the lower storey and between 0.2 and $1.7 \mathrm{~mm}$ on the upper storey. Maximum values are collected in Table II.

The objective of the last PsD test was to induce a collapse limit state on the test structure as listed in Table I. ID values attained 3.8\% and 3.5\% at the upper and lower storey, respectively. Total joint rotations in the interior frame approached or exceeded the $35 \mathrm{mrad}$ value in all beamto-column joints. Visual inspection of the structure and examination of test results revealed that the behaviour of beam-to-column joints and column base joints was comparable to that observed in the previous PsD test. No sign of failure could be seen in any of the connection components and composite columns remained undamaged. However, yielding of base plate anchors was more evident with base plate rotations reaching up to $18.5 \mathrm{mrad}$. Gaps left between concrete slab and steel column faces reached maximum values of $4.5 \mathrm{~mm}$ on the lower storey and $3.2 \mathrm{~mm}$ on the upper storey. Relevant values are collected in Table II. Additional information about test results can be found in [24, 33].

An additional correlation between test results and results of identification will be obtained by considering linearized modal frequencies of the structure identified during PsD tests by means of a linear spatial model proposed by Molina et al. [35]. For brevity, we show in Table III only the initial and final values of the relevant frequencies for each PsD test, associated with the main vibration modes of moment-resisting frames depicted in Figure 4(b). These modes are commented in [36].

(a)



(b)

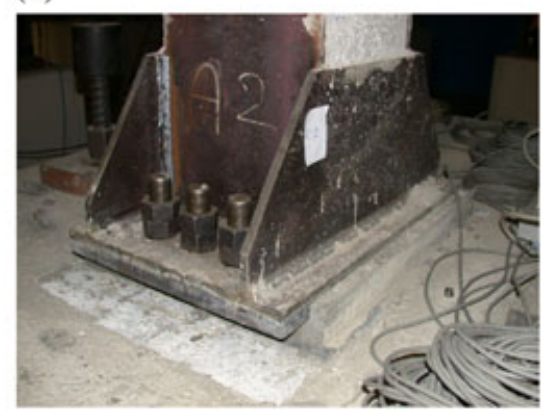

Figure 5. PsD test with PGA equal to 1.4g: (a) concrete failure on the exterior side of a joint at the lower storey; (b) grout removed under an interior column base plate. 
O. S. BURSI ET AL.

Table III. Estimated linear frequency values for different PGA levels.

\begin{tabular}{|c|c|c|c|c|}
\hline \multirow[b]{2}{*}{ PGA } & \multicolumn{2}{|c|}{ Mode 1 frequency } & \multicolumn{2}{|c|}{ Mode 2 frequency } \\
\hline & Initial value $(\mathrm{Hz})$ & Final value $(\mathrm{Hz})$ & Initial value $(\mathrm{Hz})$ & Final value $(\mathrm{Hz})$ \\
\hline $0.10 g$ & 2.31 & 2.07 & 7.52 & 7.35 \\
\hline $0.25 g$ & 2.07 & 1.96 & 7.35 & 7.06 \\
\hline $1.40 g$ & 1.96 & 1.36 & 7.06 & 5.52 \\
\hline $1.80 \mathrm{~g}$ & 1.36 & 1.14 & 5.52 & 5.38 \\
\hline
\end{tabular}

\section{PARAMETRIC IDENTIFICATION OF THE CONDENSED 2-DOF SYSTEM}

The parametric identification described above was applied to the three-dimensional structure depicted in Figure 4(b), subject to the four levels of PGA reported in Table I. The identification algorithm described at length in $[5,20]$ minimised the objective function $Q(t, \mathbf{p})$ expressed in $(5)$. In greater detail, $Q(t, \mathbf{p})$ was extended to a 2-DOF system as follows:

$$
Q(j, \mathbf{p})=\sum_{i=1}^{2}\left\|\sum_{k=0}^{N-1}\left[\operatorname{SPEC}_{x_{i}}^{(\gamma)}[j, k ; \mathbf{p}]-\operatorname{SPEC} C_{x_{i m}}^{(\gamma)}[j, k]\right]\right\| \rightarrow \mathbf{p}_{i d}(\bar{t}=\bar{j} \Delta t)=\arg \left[\min _{\forall \mathbf{p}, j=\bar{j}} Q(j, \mathbf{p})\right]
$$

where $\mathbf{p}=\left\{k_{11}, k_{12}, k_{22}, \beta_{1}, \beta_{2}, \gamma_{1}, \gamma_{2}, n_{1}, n_{2}, s_{1}, s_{2}, \mu_{s 1}, \mu_{s 2}\right\}$ defines the vector of linear, hysteretic and slip parameters, respectively, referred to the system (21). $S P E C_{x_{i m}}^{(\gamma)}[j, k]$ and $S P E C_{x_{i}}^{(\gamma)}[j, k ; \mathbf{p}]$ are values of computed and measured spectrogram, respectively, evaluated at each discrete time instant $j \Delta t$ and frequency $k \Delta f$, respectively, for the $i$-th storey response; $\gamma$ is a short time analysis window while $N$ defines the number of frequency samples [21].

\subsection{Results of identification}

The acceleration signals, corresponding to the four PsD tests listed in Table I, were characterised by a sampling frequency of $100 \mathrm{~Hz}$ and duration of $20 \mathrm{~s}$. Hence, the computed spectrograms in (24), used the whole information contained in signals, with a Hanning window of 100 samples. A pattern search algorithm available in the software package MATLAB (Mathematical Computing Software, Natick, Massachusetts, United States) [37] was used to minimise (24). Moreover, $\Delta t=0.1 \mathrm{~s}$ and $\Delta f=0.05 \mathrm{~Hz}$ were adopted. The entailing results of the parametric identification are illustrated in Figure 6, where for brevity: both hysteretic responses of the bottom and of the top storey provided by PsD tests at $1.4 \mathrm{~g}$ and $1.8 \mathrm{~g}$ PGA are depicted in the left-hand side; the corresponding hysteretic loops determined by means of $\mathbf{p}$ from (24) are shown in the right-hand side. As expected and because of the minimisation process in (24), the agreement is generally good.

Nonetheless, by means of Figure 7 and Table IV, we can appreciate differences between dissipated energies of experimental and identified hysteretic loops relevant to two storeys for higher PGA levels. Discrepancies must be ascribed to the 2-DOF chain-like model assumed for the nonlinear restoring force vector $\mathbf{f}=\left(f_{1}, f_{2}\right)^{T}$ in Equation (22). The assumption cannot completely capture the distribution of nonlinear phenomena summarised in Table II. On the other hand, it is not straightforward to combine $\mathbf{f}=\left(f_{1}, f_{2}\right)^{T}$ in the nonlinear range.

Moreover, total energy values at upper and lower storeys, dissipated by the actual structure and reported in Table IV are similar. This trend reflects the comparable amount of IDs and slips per storey collected in Table II.

The instantaneous estimates of the time-varying coefficients of $\mathbf{K}_{e l}$ in (19) are depicted in Figure 8 for different PGA levels. They reflect the stiffness degradation of the structure during the whole test sequence and govern the frequency reduction shown in Table III.

To better appreciate the evolution of some Bouc-Wen model parameters including slip, we introduce an analytic representation of real-valued response signals [11], which retrieves the positive frequency components of the Fourier transform of signals, with no loss of information. Therefore, we define the amplitude of a generic signal $x(t)$ 
$1.4 \mathrm{~g}$
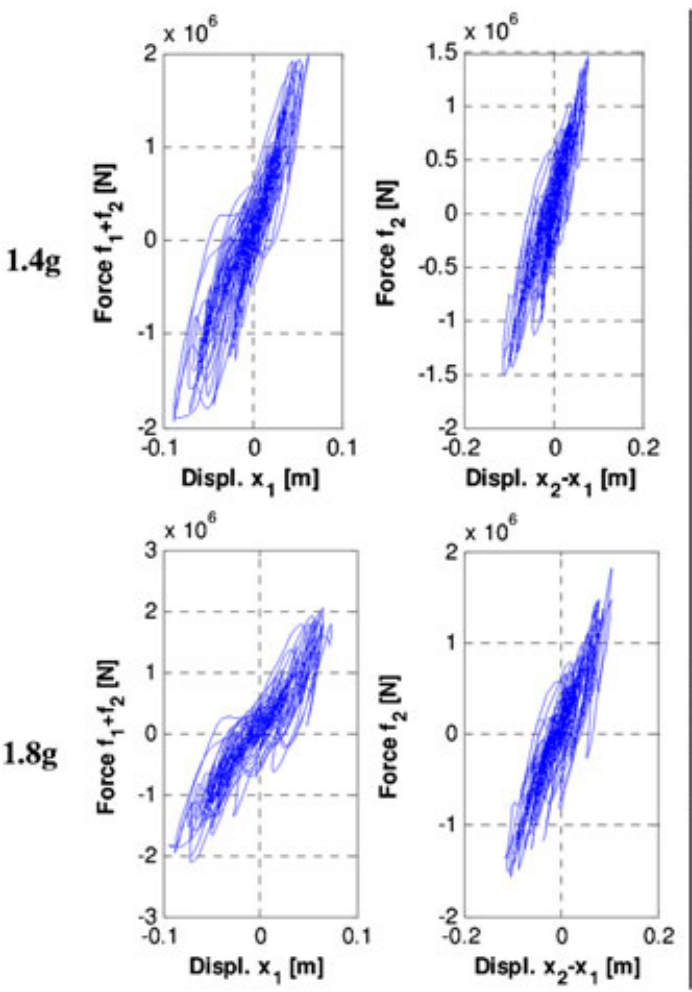


Figure 6. Comparison between experimental (left-hand side) and identified (right-hand side) hysteretic loops relevant to the condensed 2-DOF system.
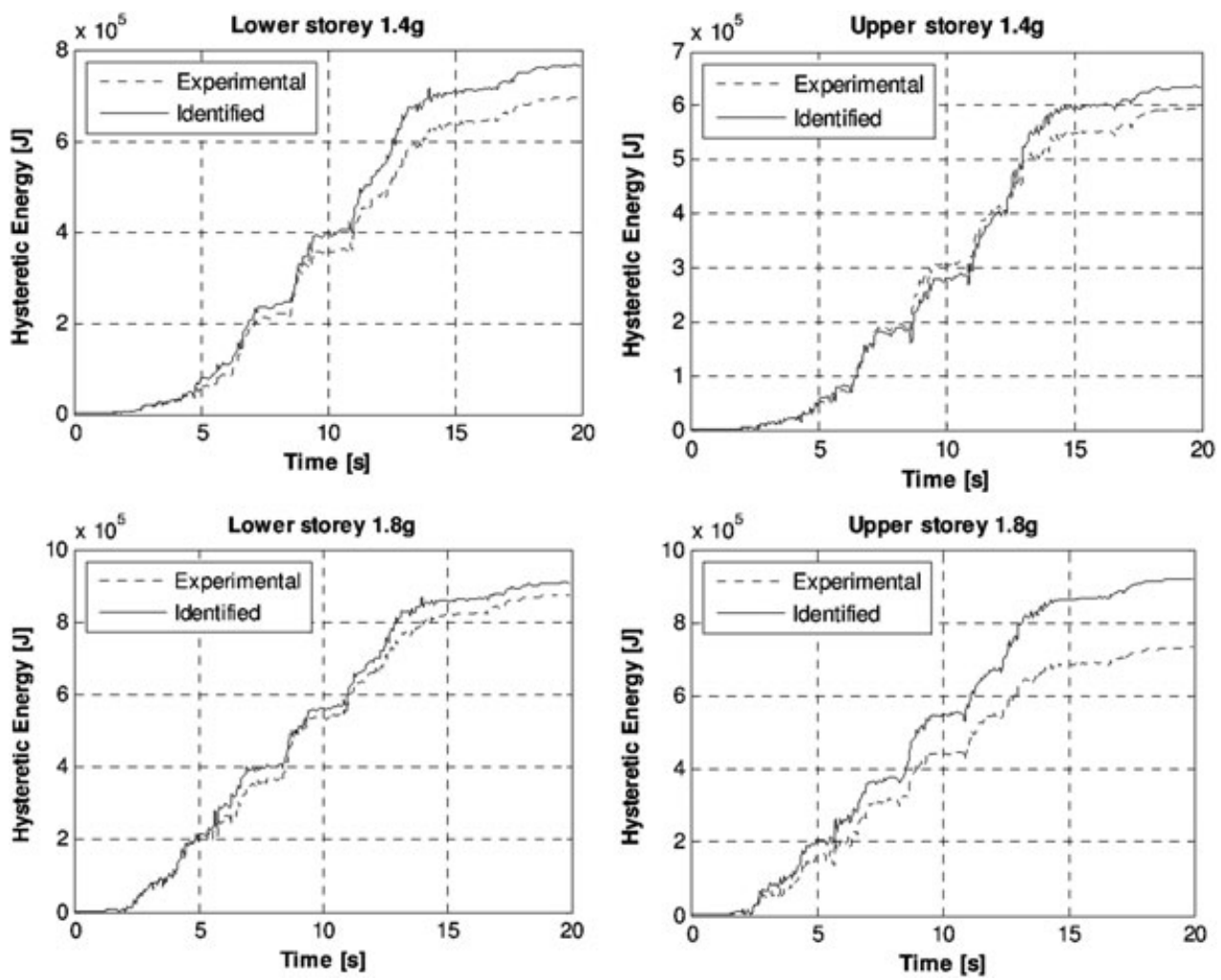

Figure 7. Comparison between identified and experimental dissipated hysteretic energy at two storeys for $1.4 g$ and $1.8 g$ PGA levels. 
Table IV. Dissipated energy from storeys of the actual structure and percentage errors with respect to values provided by the identified nonlinear degrading model of Equation (21).

\begin{tabular}{lcccr}
\hline & \multicolumn{2}{c}{$1.4 g$} & \multicolumn{2}{c}{$1.8 g$} \\
\hline & Dissipated energy [J] & Error [\%] & Dissipated energy [J] & Error [\%] \\
\hline Lower storey & 683,440 & 11.10 & 862,800 & 5.11 \\
Upper storey & 594,500 & 7.32 & 721,530 & 25.30 \\
\hline
\end{tabular}
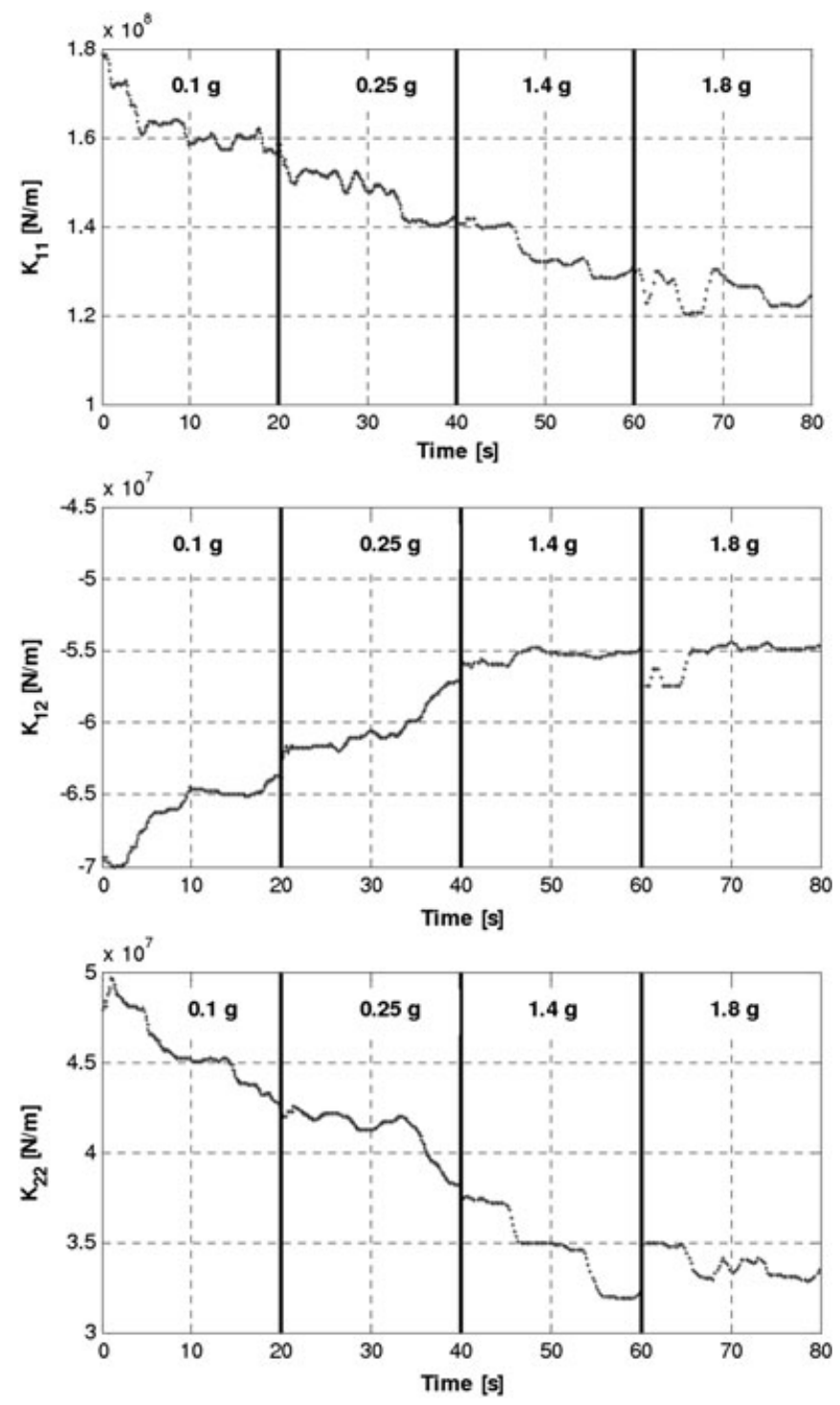

Figure 8. Instantaneous estimation of the time-varying coefficients $k_{11}, k_{12}$ and $k_{22}$ as a function of time for different PGA levels.

$$
\left|x_{a}(t)\right|=\sqrt{x^{2}(t)+\hat{x}^{2}}(t)
$$

where $\hat{x}(t)$ denotes the Hilbert transform of $x(t)$ and $x_{a}(t)$ indicates the analytic signal. In time domain, the Hilbert transform $\hat{x}(t)$ is defined as 
NONLINEAR IDENTIFICATION OF A STEEL-CONCRETE FRAME STRUCTURE


Figure 9. Amplitude of $x_{2}(t)$ and instantaneous values of $\beta_{i}$ and $\gamma_{i}$ for different values of PGA. 


$$
\hat{x}(t)=\frac{1}{\pi} \text { p.v. } \int_{-\infty}^{\infty} \frac{x(\tau)}{t-\tau} \mathrm{d} \tau
$$

by means of the Cauchy principal value (p.v.) [11]. Equation (25) was applied to the upper storey displacement $x_{2}(t)$ of (21) (see the top part of Figure 9), that well reflects a significant amount of
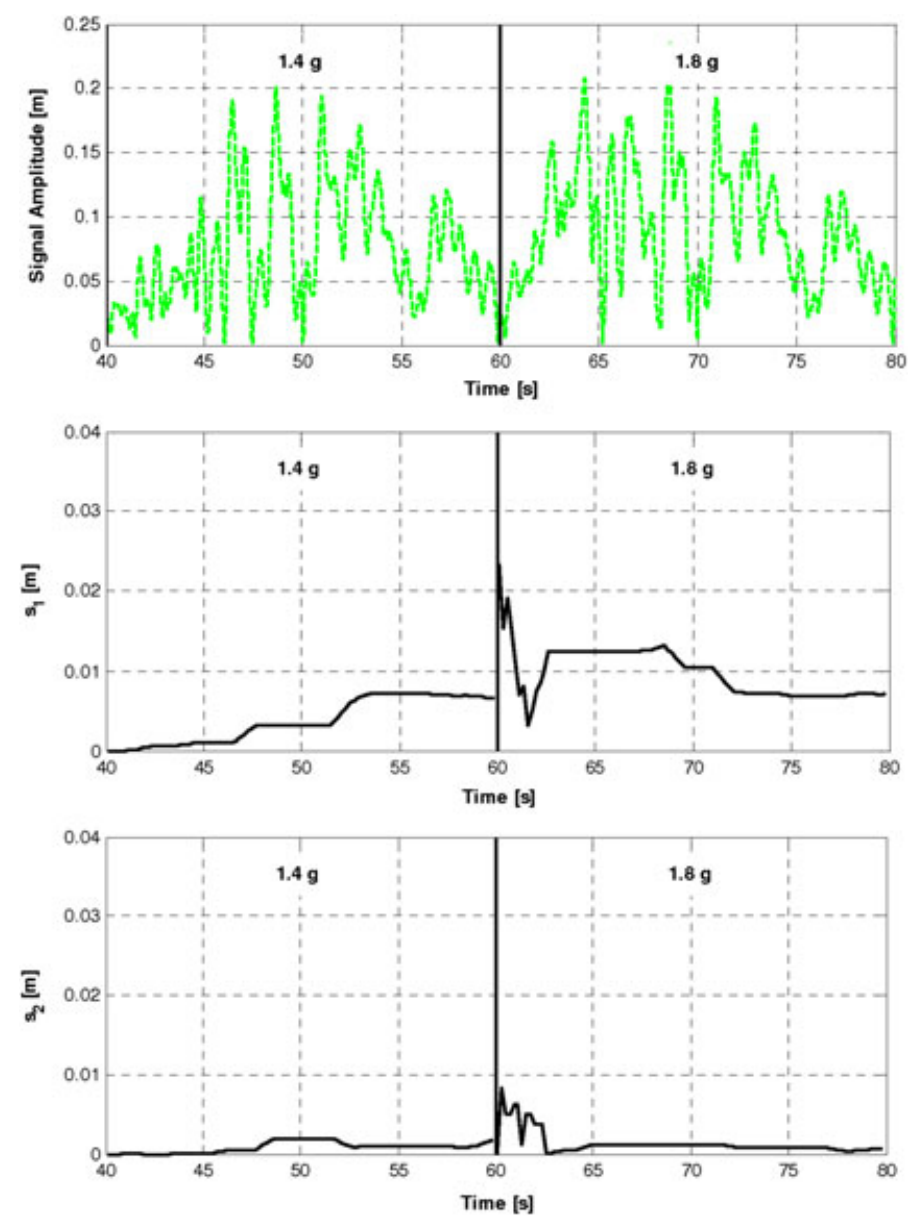

Figure 10. Amplitude of $x_{2}(t)$ and instantaneous values of $s_{i}$ for different values of PGA.


Figure 11. Hysteretic restoring force versus interstorey drift ideally obtained from the identified 2-DOF system subject to slow sinusoidal acceleration cycles for a PGA $=1.4 g$ : (a) lower storey and (b) upper storey. 
nonlinearity activated in the 2-DOF system, as a function of the PGA level. From the same figure, a careful reader can observe the instantaneous variation of $\beta_{i}$ and $\gamma_{i}$. As expected, for higher levels of PGA nonlinearity is evident, and therefore, Bouc-Wen model parameters exhibit a small variation or, in other words, they tend to stable values.

Figure 10 shows the estimates of slip parameters $s_{i}$ of Equation (19) with respect to the amplitude of $x_{2}(t)$ for higher excitation levels. Also in this case, the instantaneous estimation of these coefficients tends toward specific values of $s_{i}$, half of the total slip per storey, for the highest excitation. These values have to be correlated to sums of experimental gaps per storey, whose maximum single values are gathered in Table II.

Besides the degradation in stiffness shown in Figure 8 via the identified coefficients of $\mathbf{K}_{e l}$, defined in (18), we plotted in Figure 11 the response of the 2-DOF identified frame model in terms of restoring forces versus IDs, when subject to a sinusoidal excitation with amplitude equal to $1.4 \mathrm{~g}$. The degradation in stiffness exhibited by the model without the randomness introduced by the earthquake is evident.

Additional useful information can be retrieved from identified data. For instance, the two frequency values experimentally identified by a linear model [35] and reported in Table III can also be estimated from the coefficients of $\mathbf{K}_{e l}$ defined in (18). Their instantaneous values are plotted in Figure 12. The correlation with values of Table III is favourable especially for low excitation levels. In fact for higher excitation levels, that is, $1.4 \mathrm{~g}$ and $1.8 \mathrm{~g}$, the nonlinear Bouc-Wen model part present in Equation (17), greatly influences the linear and time-variant part of (17), that is, $\mathbf{K}_{e l}$. Instantaneous frequency data can also be retrieved by means of the Hilbert-Huang transform (HHT) [38]. In detail, the HHT is an empirical algorithm that is not model-based, and is designed to treat data sets that are nonstationary and nonlinear. This technique was applied to the displacement history $x_{1}(t)$ of the lower storey; we can observe from Figure 12 that only the instantaneous variation of the first modal frequency - shown by the dashed line of Figure 12 - was captured. This result highlights that: (i) a non-model-based technique like the HHT fails when a system is dominated by some modes, that is, the first mode for the structure in question - this can be appreciated from the

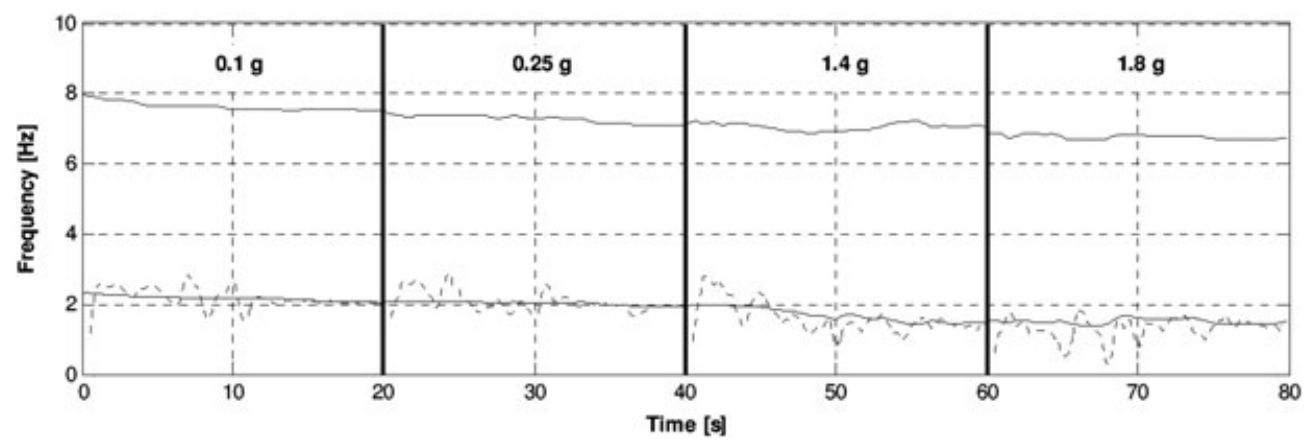

Figure 12. Evolution of the first two modal frequencies estimated from the coefficients of $\mathbf{K}_{\mathrm{el}}$ (continuous lines) and from the Hilbert-Huang transform (dashed line).

Table V. Bouc-Wen model parameters employed in Equation (21) for model validation.

\begin{tabular}{lcrrrrrrr}
\hline PGA & $\beta_{1}$ & \multicolumn{1}{c}{$\beta_{2}$} & \multicolumn{1}{c}{$\gamma_{1}$} & \multicolumn{1}{c}{$\gamma_{2}$} & $\mu_{\mathrm{s}, 1}$ & $\mu_{\mathrm{s}, 2}$ & $s_{1}$ & $s_{2}$ \\
\hline $0.1 g$ & 13.76 & 10.45 & 9.22 & 1.52 & $/$ & $/$ & 0 & 0 \\
$0.25 g$ & 15.26 & 10.55 & 8.27 & 1.38 & $/$ & $/$ & 0 & 0 \\
$1.4 g$ & 13.52 & 5.25 & 10.27 & -3.10 & $8.2 \mathrm{e}-7$ & $6.5 \mathrm{e}-7$ & 0.0038 & 0.0008 \\
$1.8 g$ & 13.20 & 5.63 & -2.56 & 0.18 & $7.6 \mathrm{e}-7$ & $6.3 \mathrm{e}-7$ & 0.0099 & 0.0013 \\
\hline
\end{tabular}


comparable ID values and energy values per storey in Tables II and IV, respectively; (ii) the technique that we propose here appears to be robust also in the nonlinear regime, see the second modal frequency estimation of Figure 12, because information is rich enough.

$0.1 \mathrm{~g}$
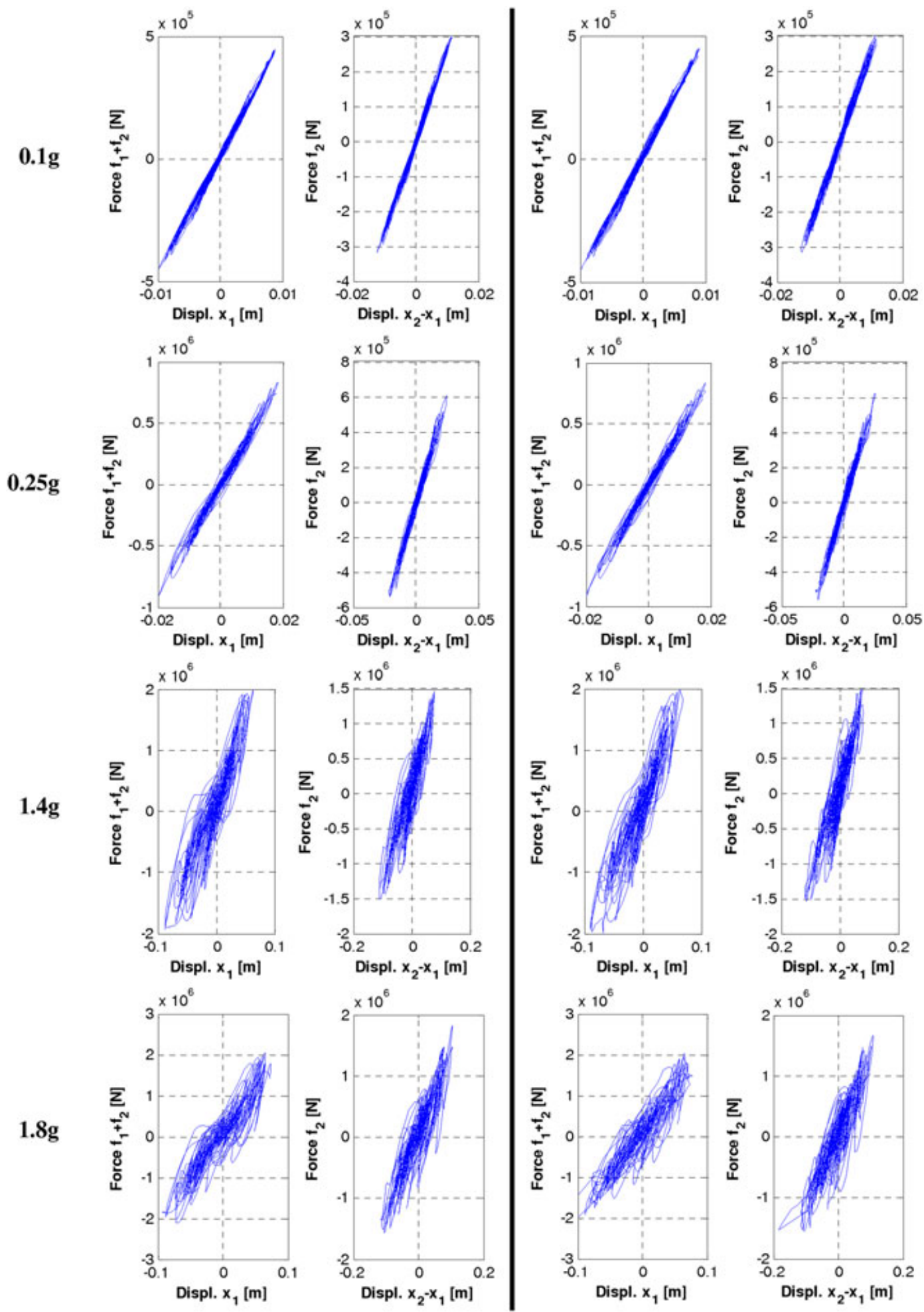

Figure 13. Comparison between experimental (left-hand side) and predicted (right-hand side) hysteretic loops for different PGA levels. 


\section{PREDICTIVE CAPABILITIES OF THE IDENTIFIED HYSTERETIC MODEL}

As we mentioned in a previous section, the identified parameters of the Bouc-Wen hysteretic model should less and less depend on PGA levels, reaching stable values. For simplicity, slip values $s_{1}$ and $s_{2}$ will also be considered constant during each PsD test, although the use of time-varying values identified in Section 5.1 seems to be reasonable [32]. Therefore, to validate the whole identification process, the linear terms $k_{11}, k_{12}$ and $k_{23}$ of (17) were assumed to maintain their timevarying nature, owing to the stiffness degradation assumption made; conversely, nonlinear parameters $\beta_{1}, \beta_{2}, \gamma_{1}, \gamma_{2}, s_{1}, s_{2}, \mu_{s 1}$ and $\mu_{s 2}$ were set by averaging instantaneous estimates, previously obtained for each PGA level. As a result, estimated parameters reported in Table V, were substituted in the system of differential Equation (21). For simplicity, $n_{1}$ and $n_{2}$ were assumed to be unitary.

Figure 13 reports the comparison between experimental and predicted hysteretic loops. For all excitation levels considered, we can see agreement between experimental data and model predictions. The application of the proposed model to the steel-concrete structure in question and subject to intense seismic excitations also demonstrates that the adoption of time-varying parameters in the linear part of the model coupled to a hysteretic model endowed with slip, does not require additional parameters - for instance parameters dependent on the dissipated energy — to account for degradation in stiffness, strength, and/or slip variation.

Additional capabilities of the identified hysteretic model can be understood from Figure 14, where errors with respect to the total dissipated energy at the lower storey of the actual structure at different PGA levels are plotted. In greater detail, the dissipated energy of the actual structure was compared with: (a) predictions provided by the model of Equation (19) without slip, and where only values of $\mathbf{K}_{e l}$ were assumed to be time-variant; (b) predictions provided by the Bouc-Wen model of Equation (21) with slip and with $\mathbf{K}_{e l}$ assumed to be time-variant. Figure 14 highlights that at lower PGA levels, a condensed 2-DOF chain-model based only on stiffness degradation appears to be sufficient to predict dissipated energies. Nonetheless, between models with and without hysteretic nonlinearity, error amounts increase significantly for higher excitation levels. In greater detail for the lower storey, at $1.4 \mathrm{~g}$ PGA we report errors equal to $30.7 \%$ and $13.0 \%$ for case (a) and (b), respectively; while at $1.8 g$ PGA we estimate errors equal to $18.7 \%$ and $11.1 \%$ for case (a) and (b), respectively. As expected these values are larger than those involved in the lower storey and gathered in Table IV for the nonlinear degrading model described by Equation (21), because nonlinear parameters of the Bouc-Wen model were set here by averaging instantaneous estimates. We evaluated similar energy errors for the upper storey. In sum, time-varying models endowed with hysteresis and slip become essential when high PGA levels are simulated.

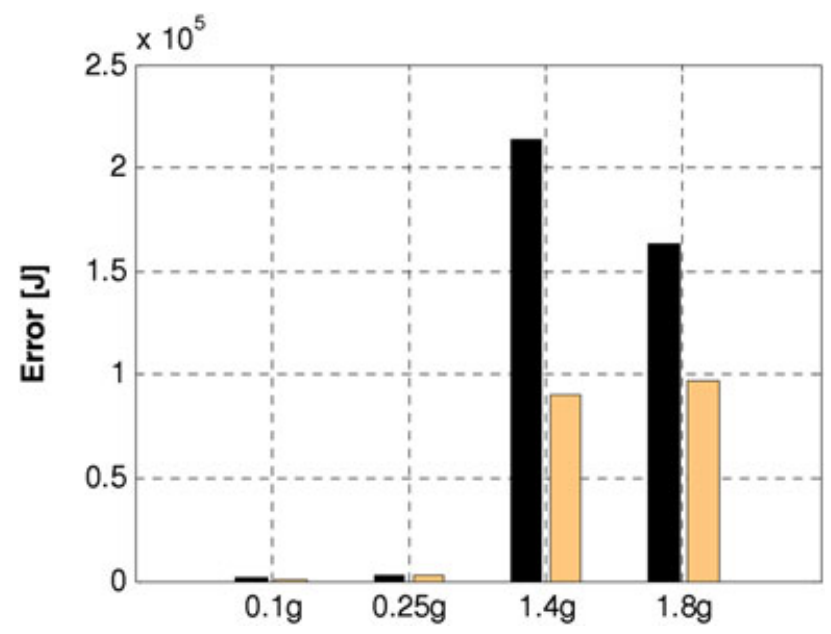

Figure 14. Error of total dissipated energy at the lower storey of the actual structure with respect to: a linear model with degradation in stiffness (black); a complete nonlinear degrading model (Equation (21)) endowed with hysteresis and slip (light brown). 


\section{CONCLUSIONS}

Structural characterisation is essential for performance-based earthquake engineering and structural control, and a fusion of experimental and numerical identification techniques holds great promise for this. We presented in this paper the identification of the hysteretic laws of a three-dimensional full scale steel-concrete composite structure - condensed to a 2-DOF chain-like system - subject to pseudodynamic tests. The relevant instantaneous coefficient values were identified via a parametric approach in conjunction with the RFS method, and allowed stiffness degradation, pinching and strength deterioration phenomena to be captured. Moreover, the use of a time-variant stiffness operator coupled to a Bouc-Wen-based model endowed with slip was also validated by means of a comparison between predicted and experimental data.

Future and necessary development of this work will cover extension of this technique to other more complex structural typologies, with further study of the exploitation of nonparametric identification techniques coupled with the RFS method.

\section{ACKNOWLEDGEMENTS}

The research leading to these results received funding from the European Community Seventh Framework Programme [FP7/2007-2013] under grant agreement $\mathrm{n}^{\circ}$ 227887. In particular, this work was developed by the partners of the WP13/JRA2 activities. Nonetheless, the conclusions drawn are those of the authors and not those of the sponsoring agency.

\section{REFERENCES}

1. Porter KA. An overview of PEER's performance-based earthquake engineering methodology. ICASP9 (July 6-9 San Francisco), 2003.

2. Molina FJ, Sorace S, Terenzi G, Magonette G, Viaccoz B. Seismic tests on reinforced concrete and steel frames retrofitted with dissipative braces. Earthquake Engng. Struct. Dyn. 2004; 33:1373-1394.

3. Ikhouane F, Manosa V, Rodellar J. Adaptive Control of a Hysteretic Structural System. Automatica 2005; 41:225-231.

4. Magonette G. Development and application of large-scale continuous pseudo-dynamic testing techniques. Phil Trans $R$ Society London A 2001; 359:1771-1799.

5. Ceravolo R, Demarie GV, Erlicher S. Instantaneous identification of degrading hysteretic oscillators under earthquake excitation. Struct. Health Monitor. 2010; 9(5):447-464.

6. Masri SF, Caffrey JP, Caughey TK, Smyth AW, Chassiakos AG. Identification of the state equation in complex nonlinear systems. Int. J. of Non-Linear Mech. 2004; 39:1111-1127.

7. Bursi OS, Ceravolo R, Demarie GV, Erlicher S, Molinari M, Zanotti Fragonara L. Identification of the damage evolution in a benchmark steel-concrete composite structure during Pseudo-Dynamic testing. CompDyn (Rhodes, June 22nd - 24th), 2009

8. Hernandez-Garcia MR, Masri SF, Ghanem R, Figueiredo E, Farrar CR. An experimental investigation of change detection in uncertain chain-like systems. J. of Sound and Vib. 2010; 329:2395-2409.

9. Loh CH, Mao CH, Huang JR, Pan TC. System identification and damage evaluation of degrading hysteresis of reinforced concrete frames. Earthquake Engng. Struct. Dyn. 2010; DOI: 10.1002/eqe.1051.

10. Ma F, Ng CH, Ajavakom N. On system identification and response prediction of degrading structures. Structural Control and Health Monitoring 2006; 13:347-364.

11. Worden K, Tomlinson GR. Nonlinearity in structural dynamics: detection, identification, and modelling. Institute of Physics Publishing: Philadelphia, PA 19106, USA, 2001.

12. Ikhouane F, Mañosa V, Rodellar J. Dynamic properties of the hysteretic Bouc-Wen model. Systems and Control Letters 2007; 56:197-205.

13. Masri SF, Caughey TK. A nonparametric identification technique for nonlinear dynamic problems. Journal of Applied Mechanics 1979; 46:433-447.

14. Benedettini F, Capecchi D, Vestroni F. Identification of Hysteretic Oscillators under earthquake loading by nonparametric models. Journal of Engineering Mechanics 1995; 121:606-612.

15. Smyth AW, Masri SF, Chassiakos AG, Caughey TK. On-line parametric identification of MDOF nonlinear hysteretic systems. ASCE Journal of Engineering Mechanics 1999; 125(2):133-142.

16. Wu M, Smyth AW. Real-time parameter estimation for degrading and pinching hysteretic models. Int. J. of Non-Linear Mech. 2008; 43:822-833.

17. Spiridonakos MD, Poulimenos AG, Fassois SD. Output-only identification and dynamic analysis of time-varying mechanical structures under random excitation: A comparative assessment of parametric methods. J. of Sound and Vib. 2010; 329:768-785.

18. Du X, Wang F. Modal identification based on Gaussian continuous time autoregressive moving average model. J. of Sound and Vib. 2010; 329:4294-4312. 
19. Hammond JK, White PR. The analysis of non-stationary signals using time-frequency methods. J. of Sound and Vib. 1996; 190(3):419-447.

20. Ceravolo R. Time-frequency analysis. Encyclopedia of Structural Health Monitoring, Chapter 26, Boller C, Chang FK, Fujino Y (eds). Wiley \& Sons Ltd: Chirchester, 2009.

21. Carmona R, Hwang WL, Torrésani BP. Practical Time-Frequency Analysis. Academic Press: San Diego, 1998.

22. Ceravolo R. Use of instantaneous estimators for the evaluation of structural damping. J. of Sound and Vib. 2004; 274:385-401.

23. Braconi A, Bursi OS, Fabbrocino G, Salvatore W, Tremblay R. Seismic performance of a 3D full-scale high ductility steel-concrete composite moment-resisting structure - Part I: Design and testing procedure. Earthquake Engng. Struct. Dyn. 2008; 37:1609-1634.

24. Braconi A, Bursi OS, Fabbrocino G, Salvatore W, Taucer F, Tremblay R. Seismic performance of a 3D full-scale high ductility steel-concrete composite moment-resisting structure - Part II: Test results and analytical validation. Earthquake Engng. Struct. Dyn. 2008; 37:1635-1655.

25. Bouc R. Modèle mathématique d'hystérésis. Acustica 1971; 24:16-25.

26. Wen YK. Method of random vibration of hysteretic systems. ASCE J. of Eng. Mech. 1976; 102:249-263.

27. Bonelli A, Bursi OS. Generalized-alpha Methods for Seismic Structural Testing. Earthquake Engineering and Structural Dynamics 2004; 33:1067-1102.

28. Baber TT, Wen YK. Random vibration oh hysteretic, degrading system. Journal of Engineering Mechanics 1981; 107(6):1069-1087.

29. Erlicher S, Point N. Pseudo potentials and loading surfaces for an endochronic plasticity theory with isotropic damage. J.of Engrg. Mech. 2008; 134(10):832-842.

30. Erlicher S, Bursi OS. Bouc-Wen-type models with stiffness degradation: thermodynamic analysis and applications. Journal of Engineering Mechanics 2008; 134(10):843-855.

31. Li SJ, Suzuki Y, Noori M. Identification of hysteretic systems with slip using bootstrap filter. Mech. Sys. and Signal Process. 2004; 18(4):781-795.

32. Sivaselvan MV, Reinhorn AM. Hysteretic Models for Deteriorating Inelastic Structures. J. of Engineering Mechanics 2000; 126(6):633-640.

33. Bursi OS, Caramelli S, Fabbrocino G, Molina J, Salvatore W, Taucer F, et al. 3D full-scale seismic testing of a steel-concrete composite building at ELSA. Report No. EUR 21299 EN, Ispra, Italy, 2004.

34. Ceravolo R, Zanotti Fragonara L, Erlicher S, Bursi OS. Parametric identification of damaged dynamic systems with hysteresis and slip. Journal of Physics Conference Series 2011; 305:1-10.

35. Molina JF, George M, Verzelletti G. Time-Domain Identification from Seismic Pseudodynamic Test Results on Civil Engineering Specimens. 2nd International Conference on Identification in Engineering Systems (Swansea): University of Wales, 1999.

36. Savadkoohi A, Molinari M, Bursi OS, Friswell MI. Finite Element Model Updating of a Semi-Rigid Moment Resisting Structure. Structural Control and Health Monitoring 2011; 18:149-168.

37. MathWorks I. MATLAB 6.1 (61st edn), MathWorks I (ed.). MathWorks, Inc.: Natick, Massachusetts, United States, 2010.

38. Huang N, Nii AO. The Hilbert Huang transform in engineering. Taylor \& Francis: Boca Raton, FL, 2005. 